\title{
Nanotextured Morphology of Poly(methyl methacrylate) and Ultraviolet Curable Poly(urethane acrylate) Blends via Phase Separation
}

\author{
Ju-Hyung Kim, ${ }^{1}$ Joon H. Kim, ${ }^{2}$ and Soonmin Seo ${ }^{3}$ \\ ${ }^{1}$ Department of Chemical Engineering, Pukyong National University, Busan 608-739, Republic of Korea \\ ${ }^{2}$ School of Chemical and Biological Engineering, Seoul National University, Seoul 151-742, Republic of Korea \\ ${ }^{3}$ College of BioNano Technology, Gachon University, Gyeonggi 461-701, Republic of Korea \\ Correspondence should be addressed to Soonmin Seo; soonmseo@gachon.ac.kr
}

Received 29 June 2015; Accepted 13 August 2015

Academic Editor: Moon Il Kim

Copyright (C) 2015 Ju-Hyung Kim et al. This is an open access article distributed under the Creative Commons Attribution License, which permits unrestricted use, distribution, and reproduction in any medium, provided the original work is properly cited.

\begin{abstract}
Domain structures of spin-coated immiscible poly(methyl methacrylate) (PMMA) and ultraviolet (UV) curable poly(urethane acrylate) (PUA) blends were studied using atomic force microscopy (AFM). Spin casting the PMMA/PUA blends in propylene glycol monomethyl ether acetate (PGMEA) was accompanied with phase separation, and PUA was subsequently cross-linked under UV radiation. Selective dissolution of PMMA in the phase-separated films was feasible using tetrahydrofuran (THF) solvent after the UV curing process, because the cured PUA material is highly stable against THF. Morphology of phase-separated structure, including domain size and height, could be controlled by varying total concentration of the blended solution, and various nanoscale features such as island-like and hole-like structures were achieved by changing weight ratio of the two immiscible polymers.
\end{abstract}

\section{Introduction}

Morphological control of immiscible polymer blends has been widely studied in regard to phase geometry and dimensions, which can lead to many practical applications [15]. Particularly, it is well known that domain structures and surface topography strongly depend on various polymer interactions (i.e., polymer-polymer and polymer-surface interactions) in the blended films, and the relative solubility of polymers in a common solvent can play a crucial role in determination of surface morphology [6]. Previous study also showed that surface structures of the blended films of polystyrene (PS) and poly(methyl methacrylate) (PMMA) are remarkably changed by varying the film thickness [7]. Spin-coating is a simple method for fabricating thin polymer films, which facilitates precise and easy control of film thickness by rotational velocity and concentration of polymer solution $[8,9]$. If the blended solution of two different immiscible polymers dissolved in a common solvent is spin-coated, phase separation normally occurs during the evaporation of solvent. Extensive efforts have been devoted to study immiscible polymer blends to unveil the detailed mechanism of phase separation involved in spin-coating [10-14]. In addition, selective dissolution of one component in phaseseparated polymer blends provides important advantages for easy fabrication of micro- or nanosized patterns which are widely used in application fields $[15,16]$. However, various interactions, such as polymer-polymer and polymer-surface interactions, cause complexity and difficulty in control of the selective dissolution and fabrication of desired structures.

Here we present a binary immiscible polymer-blended system with high stability which enables complete selective dissolution of one component. For this work, PMMA and ultraviolet (UV) curable poly(urethane acrylate) (PUA) were used [17-19], and the phase separation of PMMA/PUA blend was well-driven via solvent evaporation. Morphological changes in the PMMA/PUA blended film according to total concentration and weight ratio of the blended solution were investigated using atomic force microscopy (AFM). Selective dissolution of PMMA in the phase-separated films 
(a)

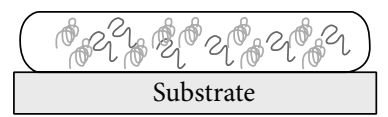

(b)
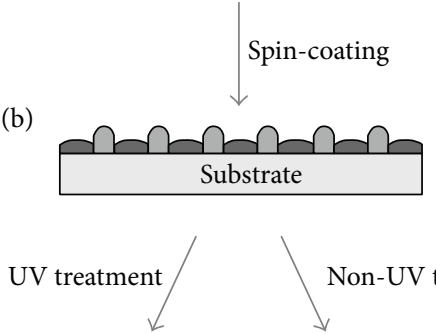

(c)

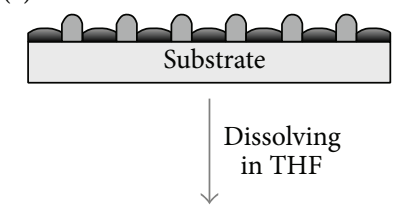

(e)

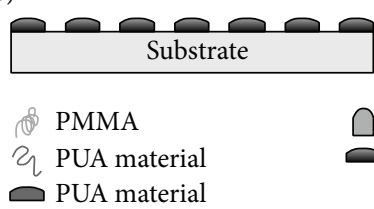

Non-UV treatment

(d)

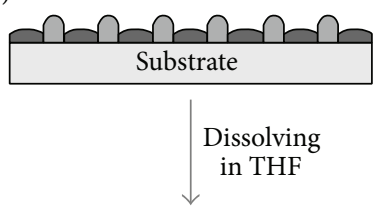

(f)

PMMA

UV-cured PUA

FIGURE 1: Schematic illustration of phase separation of PMMA/PUA upon the spin-coating process and selective dissolution before and after UV curing.

was feasible using tetrahydrofuran (THF) solvent after the UV curing process, because the cured PUA material is highly stable against THF. Morphology of phase-separated structure, including domain size and height, could be controlled by varying total concentration of the blended solution, and various nanoscale features such as island-like and holelike structures were achieved by changing weight ratio of the two immiscible polymers. These results strongly suggest great potential for various applications in the field of soft lithography, such as antireflection layers, polymer membranes, artificial superhydrophobic surfaces, and nanopatterned structures.

\section{Materials and Methods}

PMMA $(\mathrm{Mn}=11,500 \mathrm{~g} / \mathrm{mol}, \mathrm{Mw} / \mathrm{Mn}=1.08$, Polymer Source Inc.) was used as received, and the UV curable PUA mixture was synthesized in accordance with the previous reports [17]. The molecular weight of PUA could be altered by adjusting a molecular weight of a functionalized prepolymer with acrylate group, and PUA with a similar molecular weight to PMMA ( $\mathrm{Mn}=11,500 \mathrm{~g} / \mathrm{mol}$ ) was used for this work. Propylene glycol monomethyl ether acetate (PGMEA) was selected for a common solvent for the immiscible polymer blend of PMMA and PUA. The polymer-blended solutions with different concentrations were prepared to evaluate the effects. The blend with $15 \mathrm{wt} \%$ PUA and 15 wt $\%$ PMMA was used to demonstrate the complete selective dissolution of PMMA. The effects of total concentration with the same weight ratio of PMMA : PUA $(35: 65)$ were examined using three solutions: (i) $7 \mathrm{~g}$ of $10 \mathrm{wt} \%$ PMMA mixed with $13 \mathrm{~g}$ of $10 \mathrm{wt} \%$ PUA, (ii) $7 \mathrm{~g}$ of $15 \mathrm{wt} \%$ PMMA mixed with $13 \mathrm{~g}$ of $15 \mathrm{wt} \%$ PUA, and (iii) $7 \mathrm{~g}$ of $20 \mathrm{wt} \%$ PMMA mixed with $13 \mathrm{~g}$ of $20 \mathrm{wt} \%$ PUA, respectively. The PMMA/PUA blends with different weight ratios of PMMA : PUA $(3: 7,4: 6$, and $5: 5$, resp.) were also prepared by mixing $12 \mathrm{wt} \%$ of PMMA and PUA for further evaluation of the mixing effects.

Prior to spin-coating of the solutions, silicon ( $\mathrm{Si}$ ) wafer substrates were cleaned by successive sonication in trichloroethylene, acetone, and isopropyl alcohol for $5 \mathrm{~min}$ each. The polymer-blended solutions were then individually spin-coated at $3000 \mathrm{rpm}$ for $30 \mathrm{~s}$ onto the prepared Si substrates. For selective dissolution of PMMA, the spin-coated film was dipped into tetrahydrofuran (THF) for 1 min after being exposed to UV light at $\sim 365 \mathrm{~nm}$ (with a power of $4 \mathrm{~W}$ ) for $40 \mathrm{~s}$, and the film was then rinsed with deionized water and dried by blowing with $\mathrm{N}_{2}$. Note that the UV curing process was performed in the argon purged glove box, because oxygen plays a role as an inhibitor to photoinitiators. The surface morphology of each sample was analyzed by atomic force microscopy (Digital Instrument Dimension 3100) in the tapping mode, and the film thicknesses were measured using reflectometer (Nanospec, K-MAC).

\section{Results and Discussion}

Phase separation and selective dissolution in the PMMA/ PUA blend are schematically illustrated in Figure 1. The phase separation of PMMA/PUA blend was well-driven via solvent evaporation during spin-coating. The UV curable 

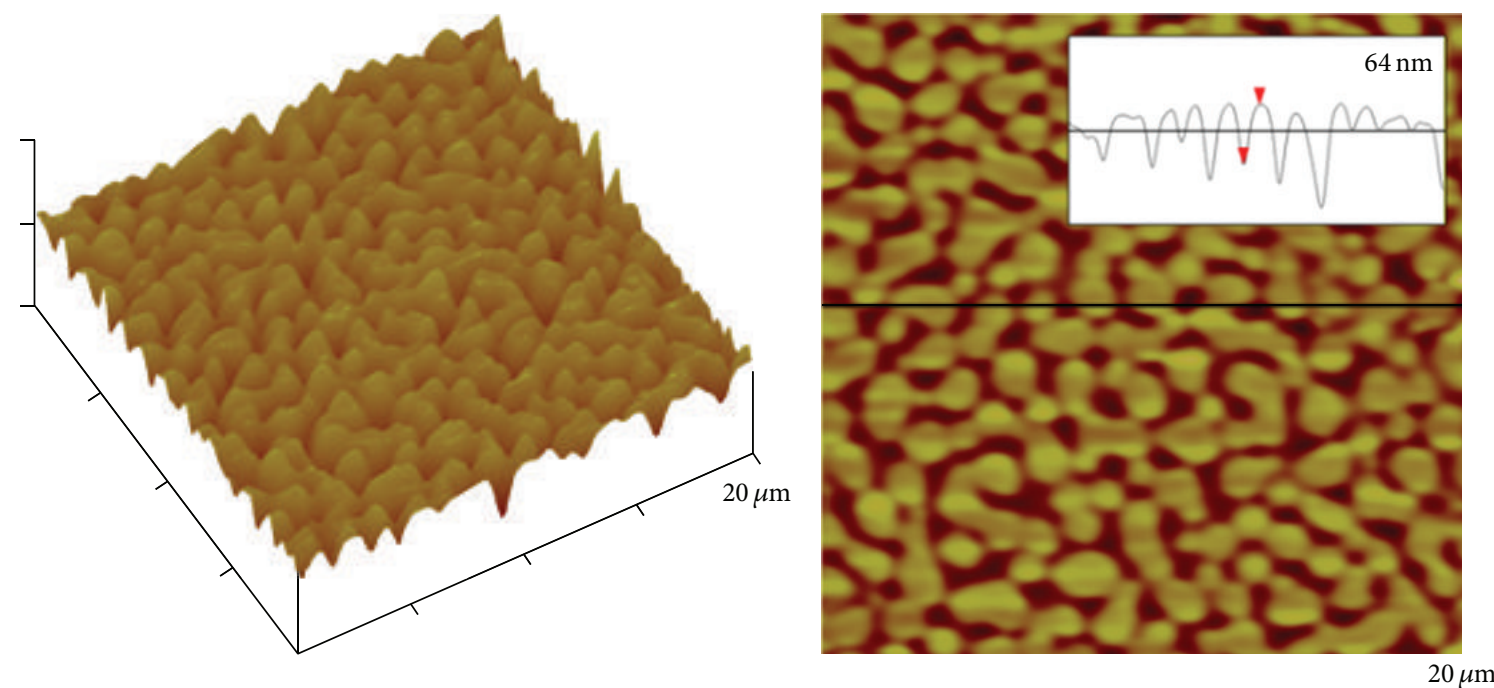

(a)
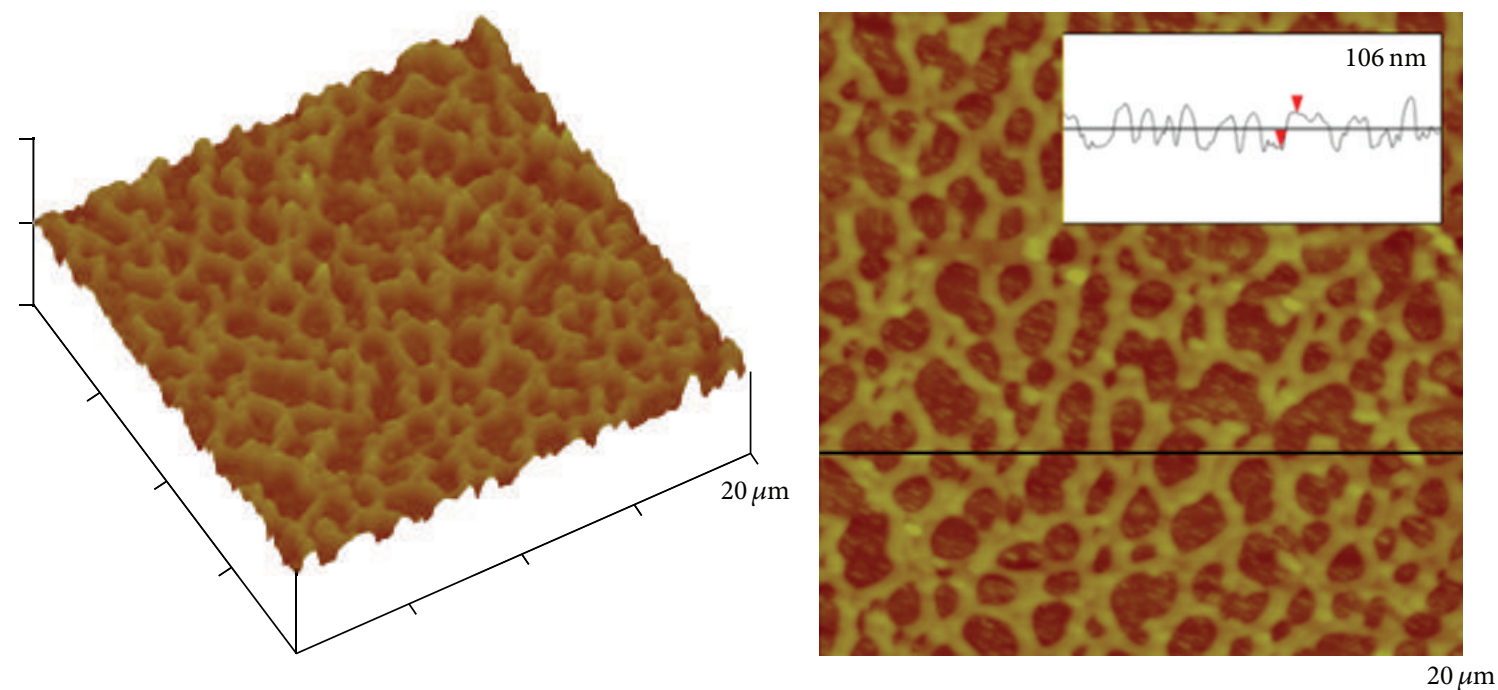

(b)
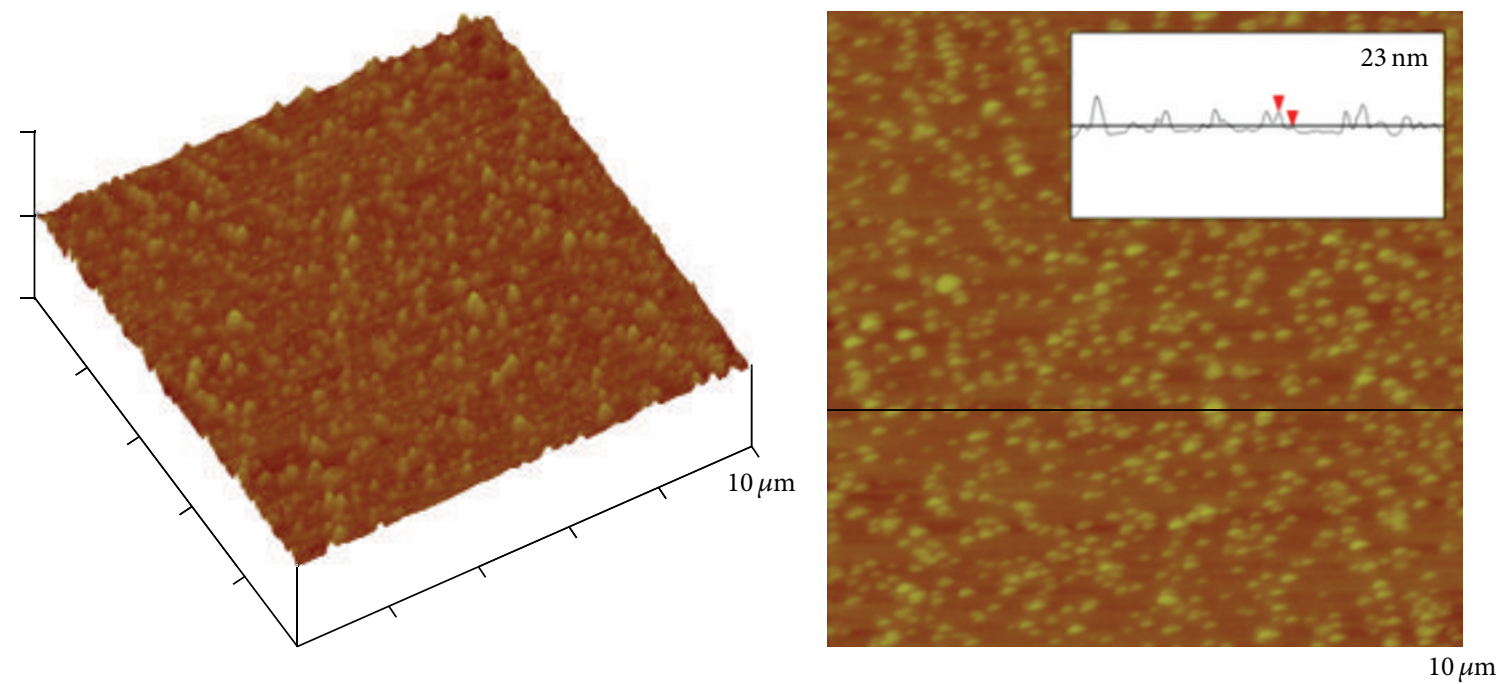

(c)

FIgure 2: Continued. 


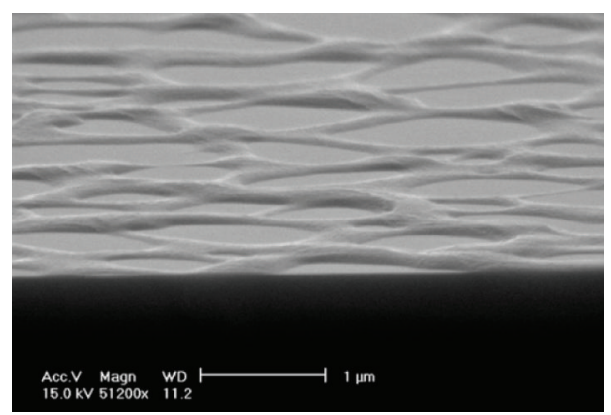

(d)

Figure 2: AFM images of (a) the PMMA/PUA (30:70) blended film after spin-coating of the 15 wt $\%$ blended solution, (b) the cured PUA domains remaining after selective dissolution of PMMA in THF, and (c) the noncured film after dissolving in THF. The height profiles are shown in insets. (d) SEM image of (b).

PUA mixture consists of functionalized prepolymer with acrylate group, photoinitiator, and releasing agent for the surface activity, and the UV curing process induces crosslinking in the PUA mixture $[17,18]$. Thus the cured PUA mixture is chemically stable against the THF treatment compared to noncured PUA and also shows high durability at high temperature $\left(\sim 300^{\circ} \mathrm{C}\right)$. As illustrated in Figure 1, the cross-linked PUA domains remain even after dissolving the blended film in THF, whereas the PMMA domains are completely dissolved in THF. It is worth noting that the noncured PUA domains are also well-dissolved in THF. These results indicate that target materials for dissolution can be selectively available via a simple UV curing process.

Figure 2(a) shows an AFM image of the PMMA/PUA ( $30: 70$ ) blended film after spin-coating of the $15 \mathrm{wt} \%$ blended solution. The bright and dark regions in Figure 2(a) are corresponding to PMMA and PUA, respectively. Phase separation in spin-coated films is normally explained by various mechanisms, such as polymer-surface interactions, surface energy differences between polymers, and fast solvent evaporation of one component in polymer blends [20, 21]. In consideration of thermodynamic behaviors, PUA material would move to the air-polymer interface to minimize interfacial free energy, because PUA has a lower surface tension than PMMA (i.e., $26 \mathrm{mN} / \mathrm{m}$ for PUA and $42 \mathrm{mN} / \mathrm{m}$ for PMMA). However, in this work, PUA mostly remains at the polymersubstrate interface, which possibly originates from spinodal decomposition due to the differences of solvent evaporation rate for each polymer and polymer solubility in the common solvent. PGMEA is a better solvent for PUA compared to PMMA, and thus the PUA-rich domains contain more PGMEA than the PMMA domains. As the solvent evaporates during spin-coating, PGMEA in PMMA drains away prior to the PUA domains which are still swollen with PGMEA. Consequently, the solvent in PMMA is quickly depleted in the spin-coating process, which leads to elevation of the PMMA domains onto the PUA-rich domains. Figure 2(b) shows the cured PUA domains remaining after the THF treatment. The bright region in Figure 2(b) corresponds to the PUA domains dispersed on the substrate after spin-coating. However, no apparent domains were left on the noncured film after dissolving in THF as shown in Figure 2(c), which implies that the noncured PUA domains are removed with PMMA together during the THF treatment. Although the solubility of PUA in THF is relatively low, the noncured PUA can be dissolved in THF due to the polymer interactions between PUA and PMMA [12].

The film thickness of each sample was measured using reflectometer, as indicated in the insets of Figure 2. Total thickness of the blended film just after spin-coating was approximately $180 \mathrm{~nm}$ and averaged height difference between PUA and PMMA was $64 \mathrm{~nm}$ (Figure 2(a)). After selective PMMA dissolution, the remaining film thickness was $\sim 106 \mathrm{~nm}$ (Figure 2(b)). The Si substrate was exposed to the air after the selective dissolution as shown in Figure 2(d), and averaged height of the cured PUA domains was $\sim 170 \mathrm{~nm}$. The height of the cured PUA domains was almost the same as the total thickness of the blended film, implying that PUA and PMMA are phase-separated on the substrate as illustrated in Figure 1(b). Note that the substrate exposure induced from the selective dissolution without additional etching process can be applied to further applications, such as antireflection layers.

Morphology of the PMMA/PUA blend, including domain size and height, can be varied with the total concentration of solution. Three different total concentrations with the same weight ratio of PMMA:PUA (35:65) were used to evaluate the effects of total concentration (see Section 2). Figure 3 shows the morphological change as the total PMMA/PUA concentration increases. Averaged height differences between the cured PUA domains and the PMMA domains before the THF treatments were $\sim 35 \mathrm{~nm}$, $\sim 72 \mathrm{~nm}$, and $\sim 157 \mathrm{~nm}$ for the $10 \mathrm{wt} \%, 15 \mathrm{wt} \%$, and $20 \mathrm{wt} \%$ blended solutions, respectively (Figures 3(a)-3(c)). After the THF treatments, the heights of the cured PUA were found to be $\sim 61 \mathrm{~nm}$ (for $10 \mathrm{wt} \%$ ), $\sim 119 \mathrm{~nm}$ (for $15 \mathrm{wt} \%$ ), and $\sim 170 \mathrm{~nm}$ (for $20 \mathrm{wt} \%$ ), respectively (Figures 3(d)-3(f)). These results indicate that both PMMA and PUA heights increase as the total concentration of the blend increases. In addition, the PMMA/PUA blends with different weight ratios of PMMA:PUA were also examined for further evaluation of the mixing effects (see Section 2). Figure 4 

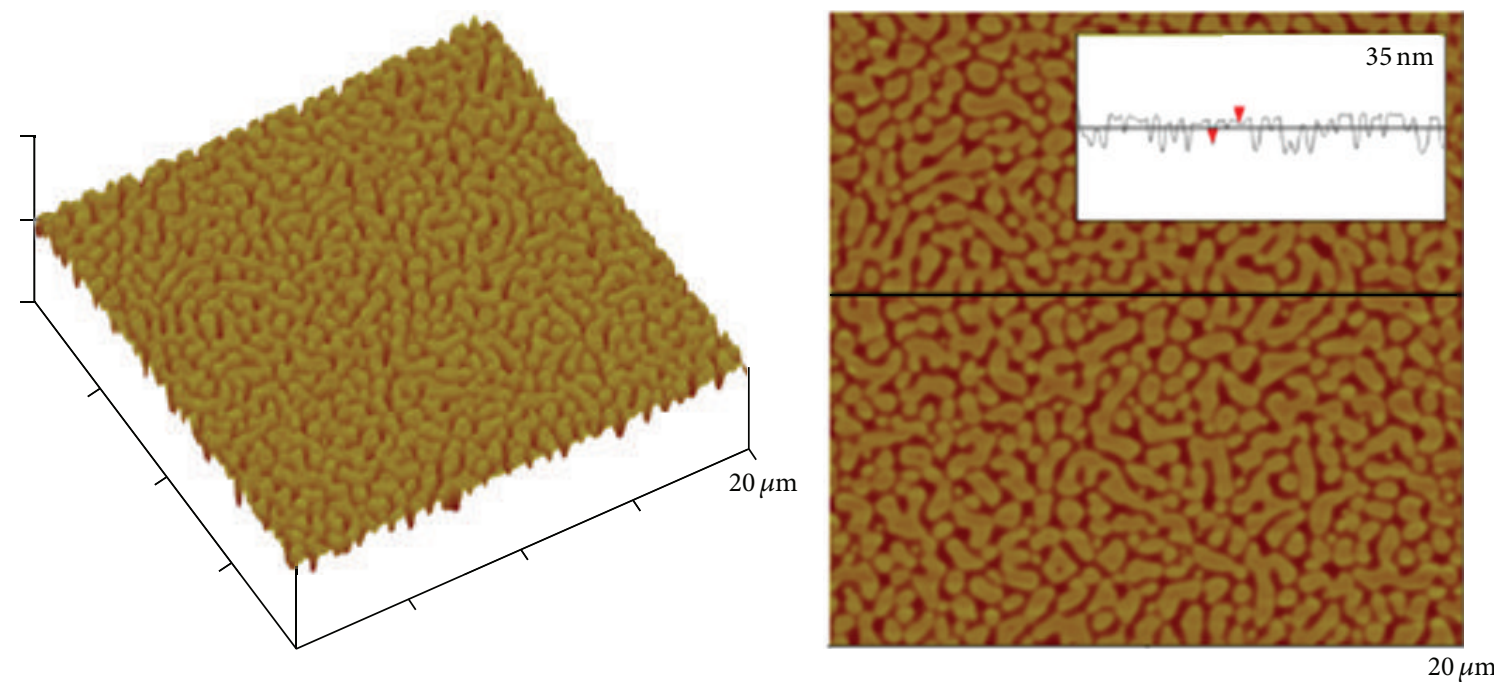

(a)
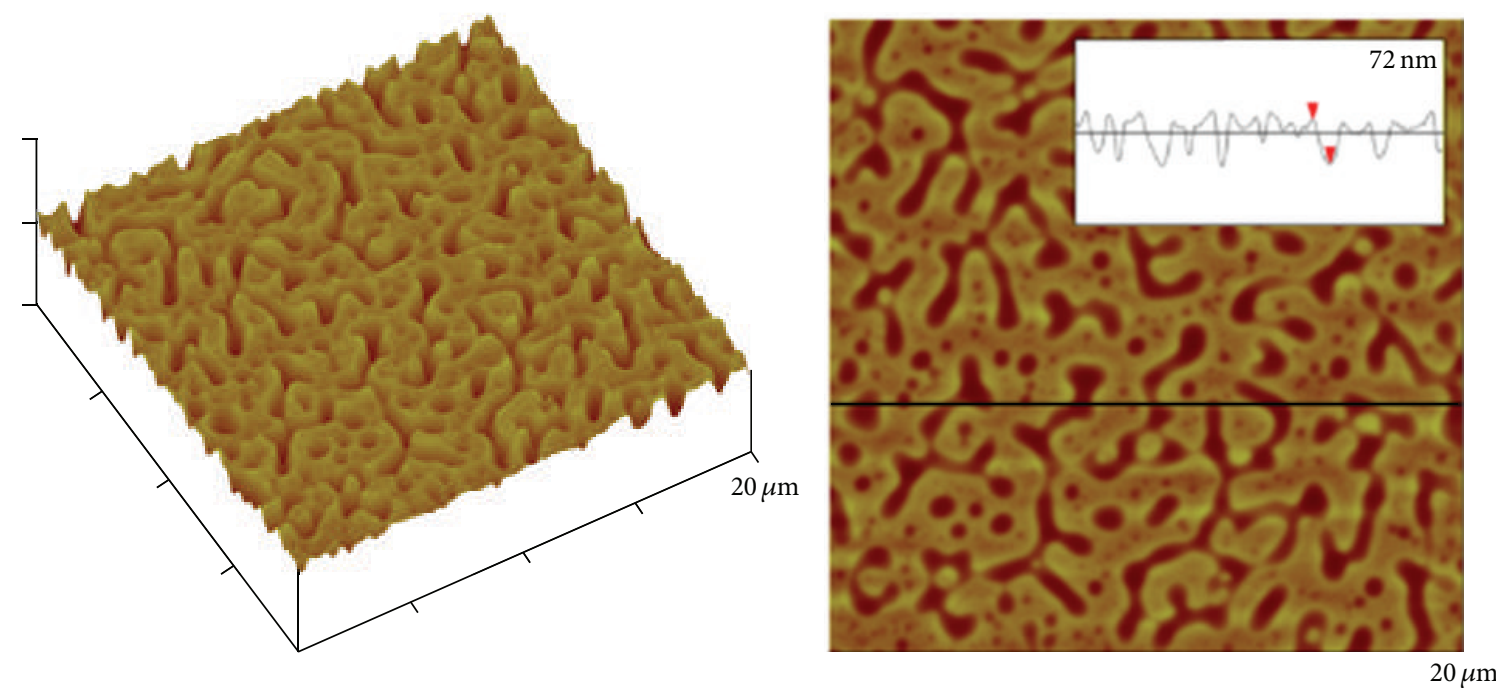

(b)
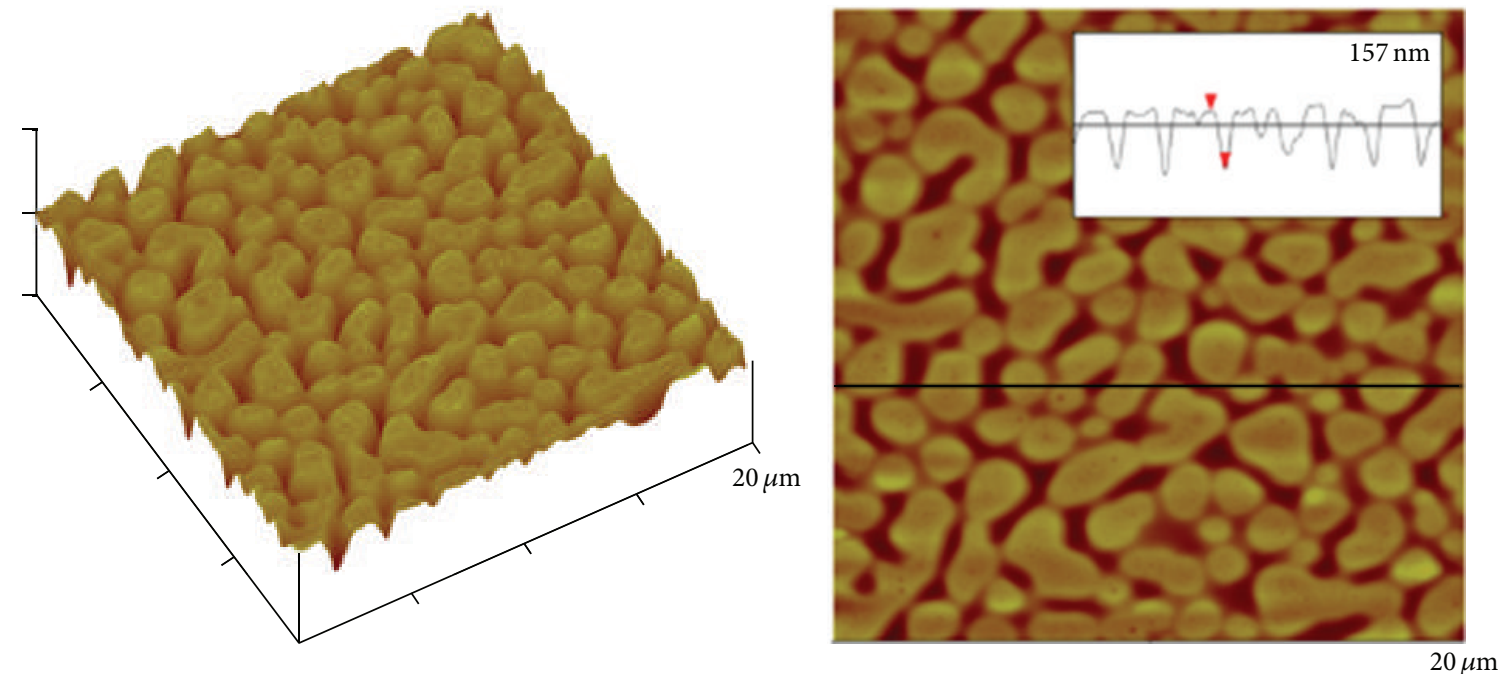

(c)

FIgure 3: Continued. 


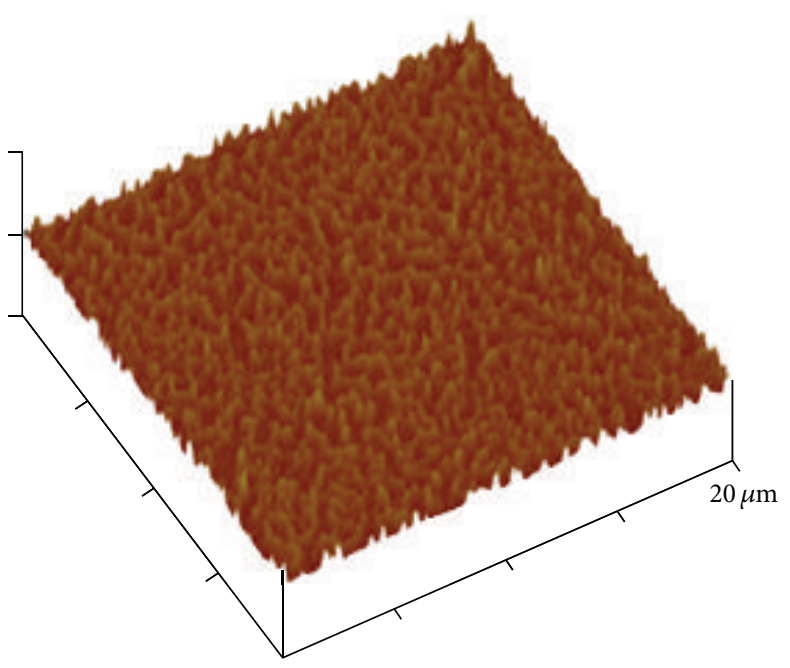

(d)

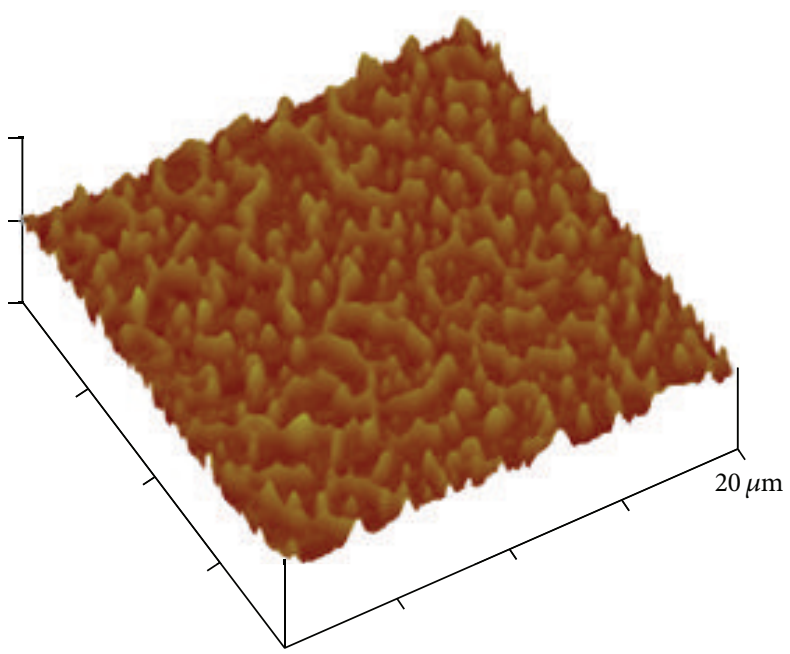

(e)
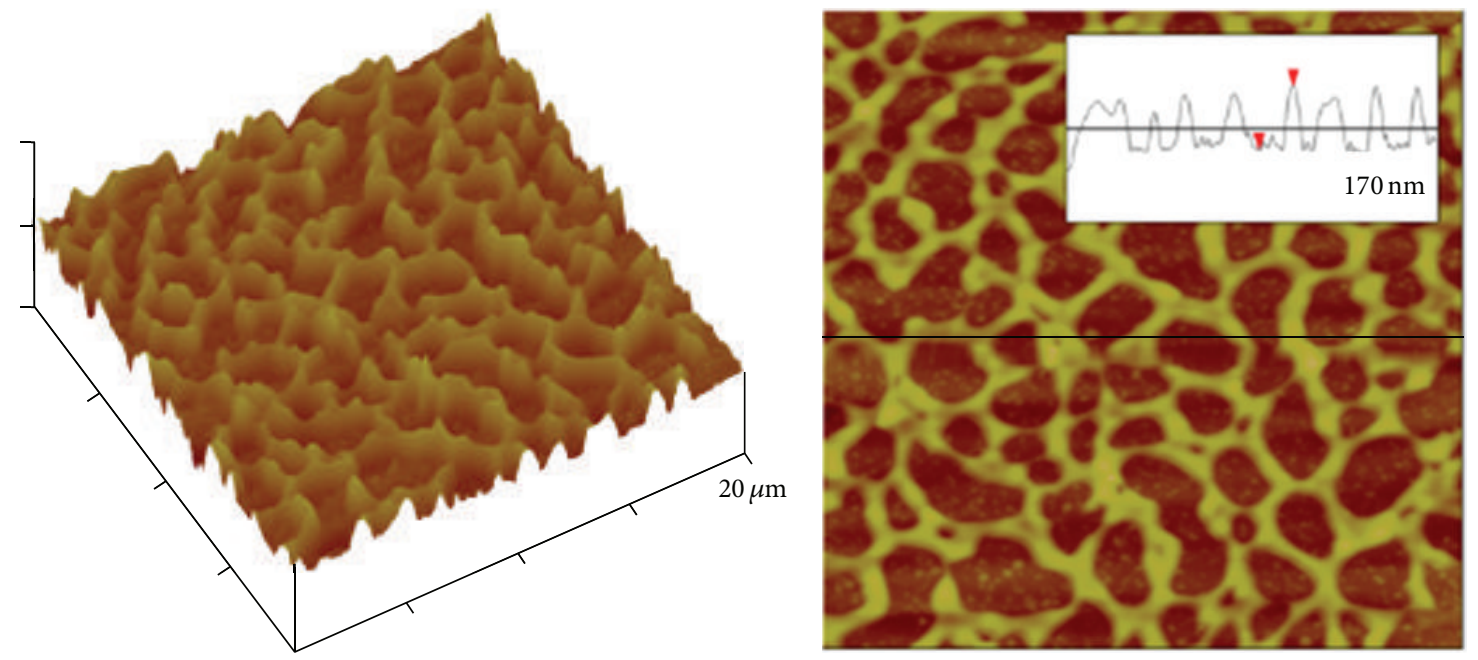

$20 \mu \mathrm{m}$

(f)

Figure 3: AFM images of the PMMA/PUA blended films with different total concentrations. The cured PUA domains and the PMMA domains before the THF treatments for (a) $10 \mathrm{wt} \%$, (b) $15 \mathrm{wt} \%$, and (c) $20 \mathrm{wt} \%$ blended solutions, and the cured PUA domains remaining after the THF treatments for (d) $10 \mathrm{wt} \%$, (e) $15 \mathrm{wt} \%$, and (f) $20 \mathrm{wt} \%$ blended solutions. The height profiles are shown in insets. 


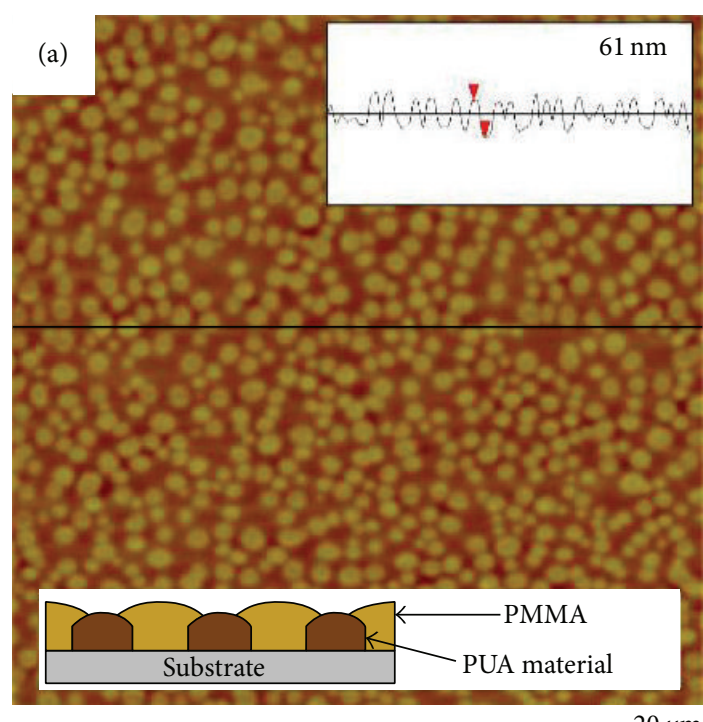

(a)

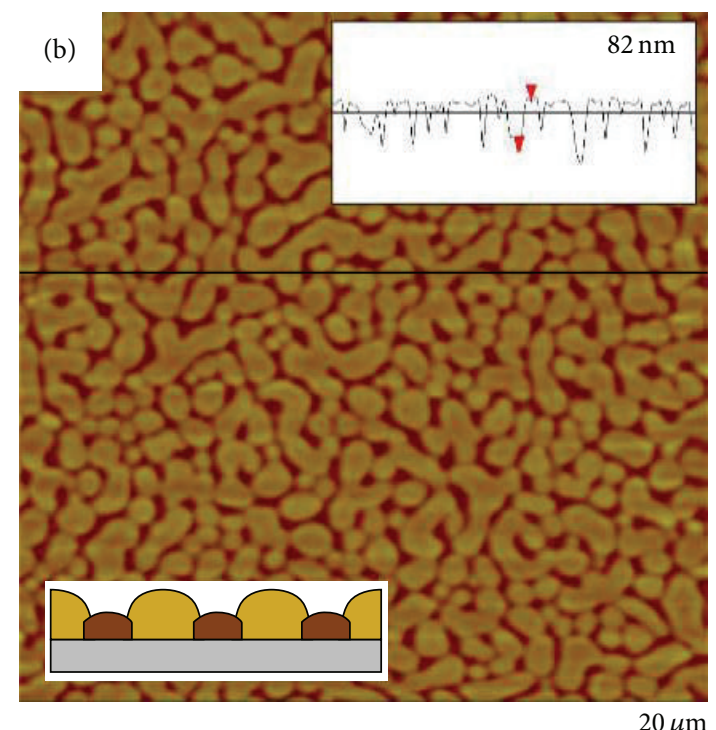

(b)

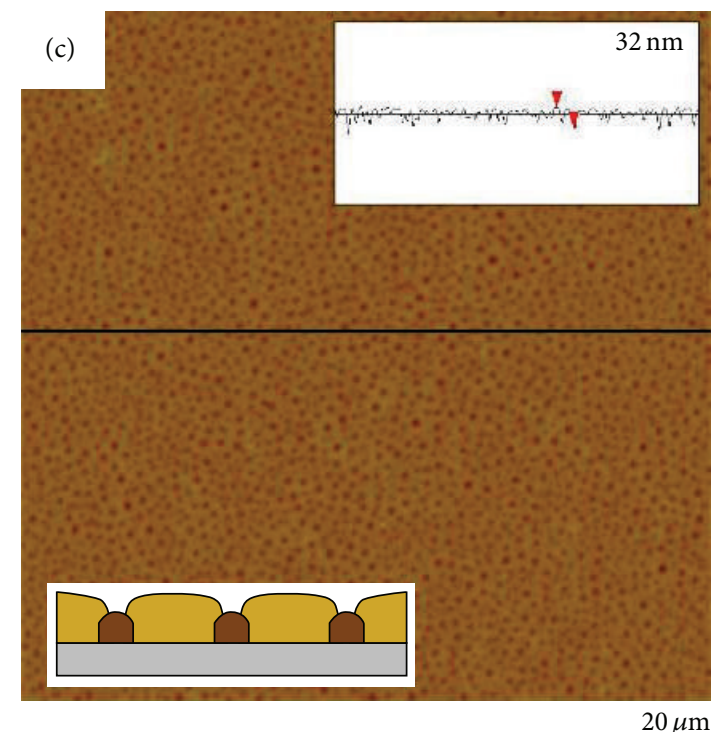

(c)

Figure 4: Morphology of the PMMA/PUA blended films with different weight ratios of PMMA : PUA in the 12 wt\% solutions. The weight ratios of PMMA : PUA are (a) $3: 7(\varphi=0.3)$, (b) $4: 6(\varphi=0.4)$, and (c) $5: 5(\varphi=0.5)$. Height profiles and schematic illustrations of the phase-separated domains are shown in insets.

shows morphology of the PMMA/PUA blended films with different weight ratios of PMMA:PUA $(3: 7,4: 6$, and $5: 5$ in the $12 \mathrm{wt} \%$ solutions). Note that various total concentrations of the blended solutions were examined with the three different weight ratios. Although the blends with the varied concentrations showed similar tendencies according to the weight ratios, the $12 \mathrm{wt} \%$ solution most specifically revealed morphological changes in the blended films. Island-like features with the diameter of $\sim 600 \mathrm{~nm}$ were clearly observed when the PMMA mass fraction $(\varphi)$ was 0.3 (i.e., PMMA/PUA $=30 / 70$ ) as shown in Figure 4(a), and the size of island-like features became larger as the value of $\varphi$ increased. When the value of $\varphi$ increased up to $\sim 0.4$, the island-like PMMA features were finally connected to each other and formed larger domains (Figure 4(b)). Island-like features completely disappeared at $\varphi=0.5$, and hole-like features with the diameter of $\sim 500 \mathrm{~nm}$ were rather found as shown in Figure 4(c). The hole diameter decreased to $\sim 100 \mathrm{~nm}$ as the value of $\varphi$ increased up to $\sim 0.6$. It is worth noting that only one phase was observed on the surface without any evidence of phase separation when the value of $\varphi$ was below 0.2 or above 0.8 , due to the excess amount of one component in the blends. These results imply that morphology of phase-separated structure with varied features can be easily controlled by changing composition of the blends. 


\section{Conclusions}

Spin-coated immiscible PMMA and UV curable PUA blends are phase-separated owing to the differences of solvent evaporation rate for each polymer and polymer solubility in the common solvent. The cross-linked PUA in the polymer-blended films provides strong chemical stability in the solvents such as THF, and thus target materials for dissolution can be selectively available via a simple curing process. The substrate exposure after film deposition also can be achieved by the selective dissolution without additional etching process, which may lead to further applications such as antireflection layers. In addition, morphology of the PMMA/PUA blends can be easily controlled by changing composition (i.e., total concentration and weight ratio) of the blends. The morphological controls include domain size, height, and nanoscale features such as island-like and holelike structures. We anticipate that these controllable structures originating from the phase separation will be applied to various engineering fields such as soft lithography.

\section{Conflict of Interests}

The authors declare that there is no conflict of interests regarding the publication of this paper.

\section{Authors' Contribution}

Ju-Hyung Kim and Joon H. Kim contributed equally to this work.

\section{Acknowledgment}

This work was supported by a research grant of Pukyong National University (Year 2014).

\section{References}

[1] M. Boltau, S. Walheim, J. Mlynek, G. Krausch, and U. Steiner, "Surface-induced structure formation of polymer blends on patterned substrates," Nature, vol. 391, no. 6670, pp. 877-879, 1998.

[2] S. Walheim, E. Schäffer, J. Mlynek, and U. Steiner, "Nanophaseseparated polymer films as high-performance antireflection coatings," Science, vol. 283, no. 5401, pp. 520-522, 1999.

[3] S. Nilsson, A. Bernasik, A. Budkowski, and E. Moons, "Morphology and phase segregation of spin-casted films of polyfluorene/PCBM blends," Macromolecules, vol. 40, no. 23, pp. 82918301, 2007.

[4] C. Huang, J. Gao, W. Yu, and C. Zhou, "Phase separation of poly(methyl methacrylate)/poly(styrene-co-acrylonitrile) blends with controlled distribution of silica nanoparticles," Macromolecules, vol. 45, no. 20, pp. 8420-8429, 2012.

[5] S. Kato and A. Sato, "Micro/nanotextured polymer coatings fabricated by UV curing-induced phase separation: creation of superhydrophobic surfaces," Journal of Materials Chemistry, vol. 22, no. 17, pp. 8613-8621, 2012.

[6] S. Walheim, M. Böltau, J. Mlynek, G. Krausch, and U. Steiner, "Structure formation via polymer demixing in spin-cast films," Macromolecules, vol. 30, no. 17, pp. 4995-5003, 1997.
[7] K. Tanaka, A. Takahara, and T. Kajiyama, "Film thickness dependence of the surface structure of immiscible polystyrene/poly(methyl methacrylate) blends," Macromolecules, vol. 29, no. 9, pp. 3232-3239, 1996.

[8] D. B. Hall, P. Underhill, and J. M. Torkelson, "Spin coating of thin and ultrathin polymer films," Polymer Engineering \& Science, vol. 38, no. 12, pp. 2039-2045, 1998.

[9] D. W. Schubert and T. Dunkel, "Spin coating from a molecular point of view: its concentration regimes, influence of molar mass and distribution," Materials Research Innovations, vol. 7, no. 5, pp. 314-321, 2003.

[10] J. S. Chiou, J. W. Barlow, and D. R. Paul, "Miscibility of bisphenol-a polycarbonate with poly(methyl methacrylate)," Journal of Polymer Science Part B: Polymer Physics, vol. 25, no. 7, pp. 1459-1471, 1987.

[11] J.-B. Lhoest, P. Bertrand, L. T. Weng, and J.-L. Dewez, "Combined time-of-flight secondary ion mass spectrometry and Xray photoelectron spectroscopy study of the surface segregation of poly(methyl methacrylate) (PMMA) in bisphenol A polycarbonate/PMMA blends," Macromolecules, vol. 28, no. 13, pp. 4631-4637, 1995.

[12] M. C. Davies, K. M. Shakesheff, A. G. Shard et al., "Surface analysis of biodegradable polymer blends of poly(sebacic anhydride) and poly(DL-lactic acid)," Macromolecules, vol. 29, no. 6, pp. 2205-2212, 1996.

[13] P. Wang and J. T. Koberstein, "Morphology of immiscible polymer blend thin films prepared by spin-coating," Macromolecules, vol. 37, no. 15, pp. 5671-5681, 2004.

[14] T. Kikuchi, M. Kudo, C. Jing, T. Tsukada, and M. Hozawa, "Electrohydrodynamic effect on phase separation morphology in polymer blend films," Langmuir, vol. 20, no. 4, pp. 1234-1238, 2004.

[15] M. Ibn-Elhaj and M. Schadt, "Optical polymer thin films with isotropic and anisotropic nano-corrugated surface topologies," Nature, vol. 410, no. 6830, pp. 796-799, 2001.

[16] J. Kim, M. Inoue, L. Zhao et al., "Tunable and flexible solventfree liquid organic distributed feedback lasers," Applied Physics Letters, vol. 106, no. 5, Article ID 053302, 2015.

[17] S.-J. Choi, P. J. Yoo, S. J. Baek, T. W. Kim, and H. H. Lee, "An ultraviolet-curable mold for Sub-100-nm lithography," Journal of the American Chemical Society, vol. 126, no. 25, pp. 77447745,2004

[18] S.-J. Choi, H. N. Kim, W. G. Bae, and K.-Y. Suh, "Modulusand surface energy-tunable ultraviolet-curable polyurethane acrylate: properties and applications," Journal of Materials Chemistry, vol. 21, no. 38, pp. 14325-14335, 2011.

[19] J.-H. Kim, S. H. Hong, K.-D. Seong, and S. Seo, "Fabrication of organic thin-film transistors on three-dimensional substrates using free-standing polymeric masks based on soft lithography," Advanced Functional Materials, vol. 24, no. 16, pp. 2404-2408, 2014.

[20] A. Bernasik, J. Włodarczyk-Miśkiewicz, W. Łuzny et al., "Lamellar structures formed in spin-cast blends of insulating and conducting polymers," Synthetic Metals, vol. 144, no. 3, pp. 253-257, 2004.

[21] J. Jaczewska, A. Budkowski, A. Bernasik et al., "Humidity and solvent effects in spin-coated polythiophene-polystyrene blends," Journal of Applied Polymer Science, vol. 105, no. 1, pp. 67-79, 2007. 

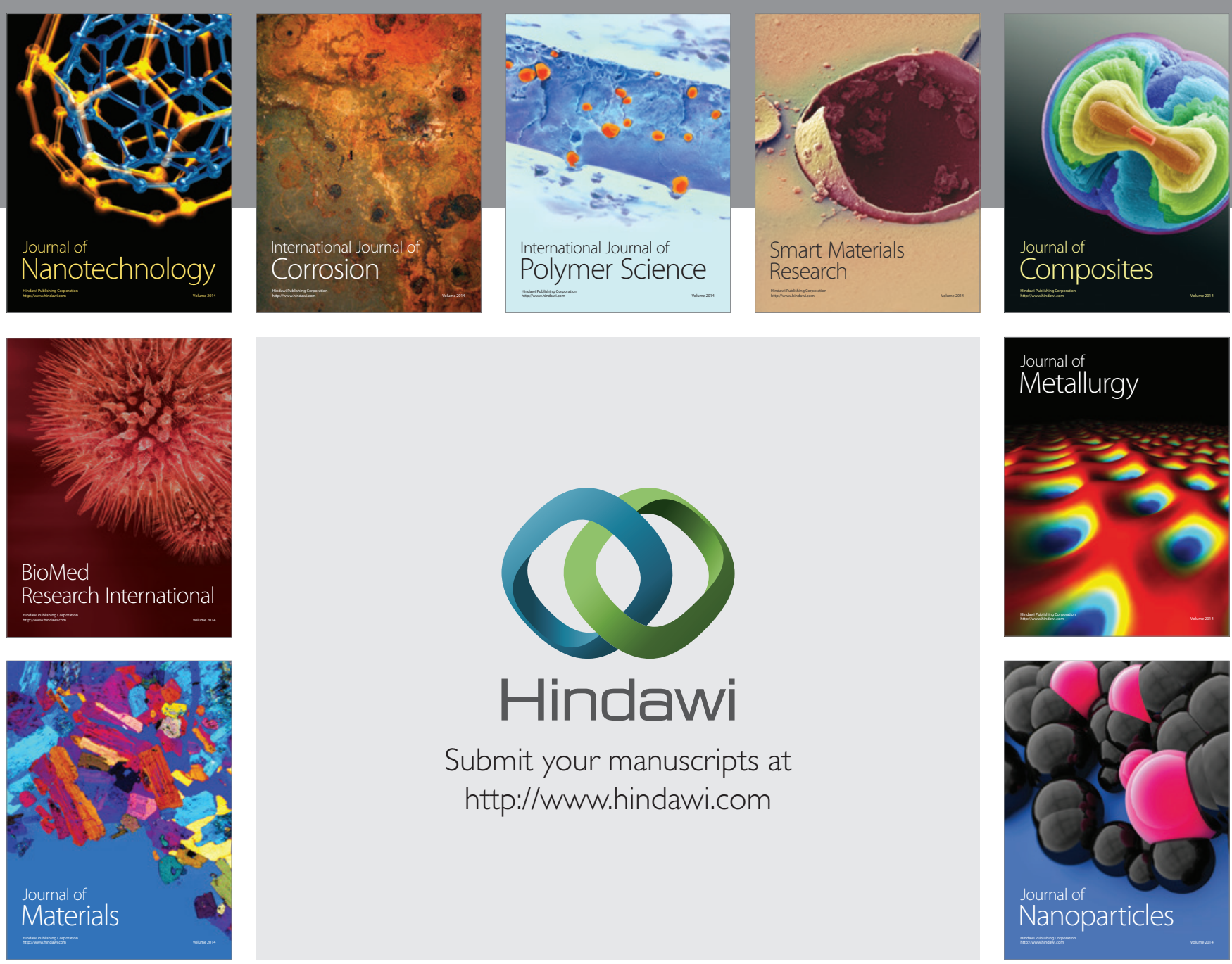

Submit your manuscripts at http://www.hindawi.com
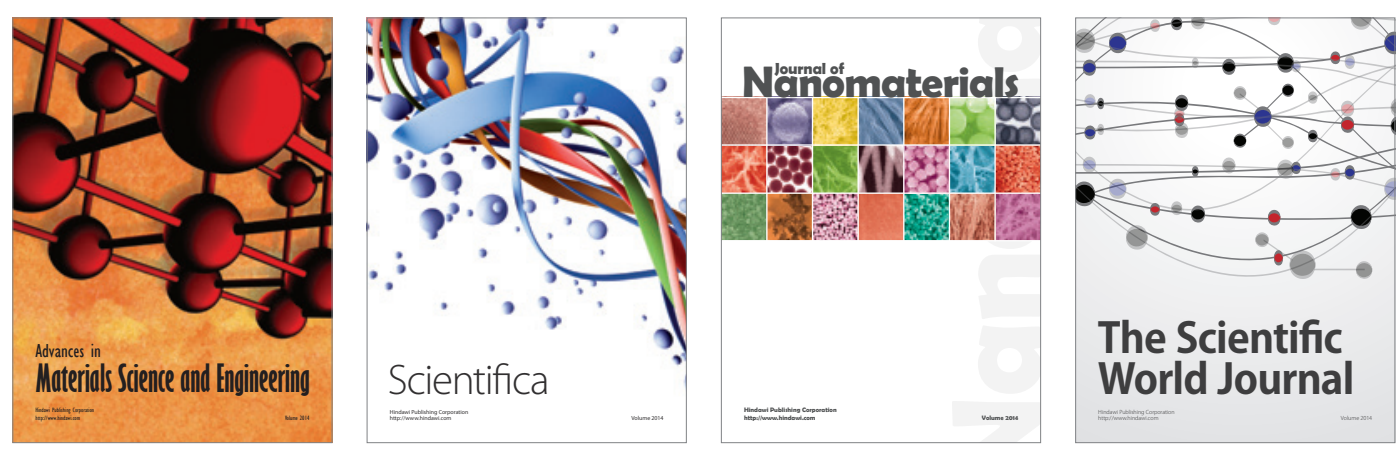

\section{The Scientific World Journal}
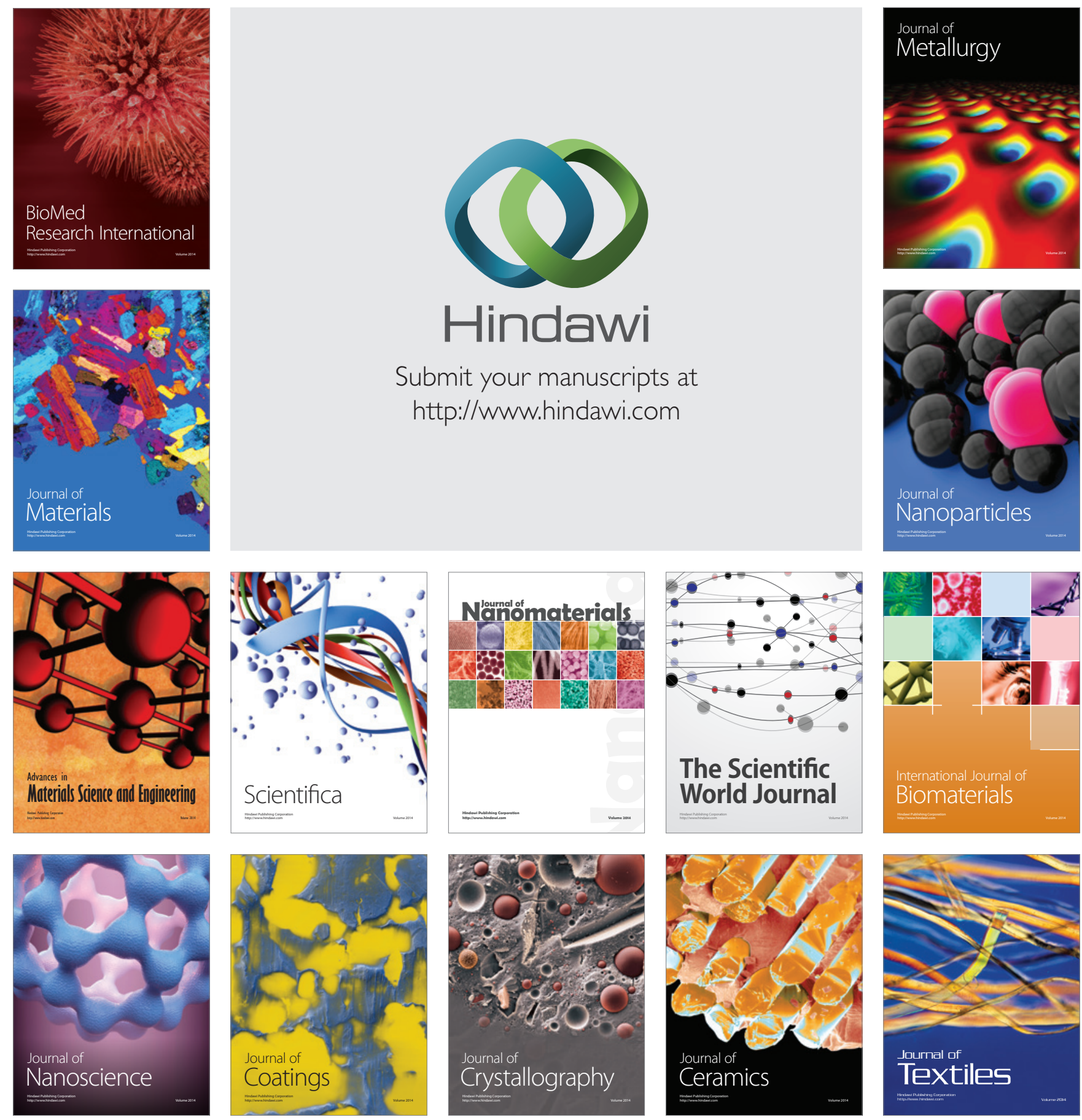